\title{
Overseas Migration and the Well-being of Those Left Behind in Rural Communities of Bangladesh
}

\author{
Remittances not only contribute to raising \\ economic well-being but also can also modify the \\ behaviour of the sending communities
}

By Abdullahel Hadi*

The cost and benefit issues of overseas migration in countries of origin is a hotly debated subject in terms of the development process. International migration not only produces large inflows of valuable remittances but also offers an outlet for frustrated unemployed workers who might otherwise present serious domestic problems. As a result, policy makers in many less

- Senior Research Sociologist, Research and Evaluation Division, Bangladesh Rural Advancement Committee (BRAC), 75 Mohakhali, Dhaka, Bangladesh. Fax (880-2) 883542: e-mail: shirsha@bangla.net. The article is based on a paper prepared for the Workshop on Migration and Sustainable Livelihood, which was held at Sussex University in Brighton, United Kingdom, from 5 to 6 June 1998. 
developed countries encourage overseas migration in order to reduce unemployment at home and accumulate valuable foreign exchange to stimulate economic growth. More than 100 million people were living outside their country of origin in the 1980s, according to a United Nations estimate (Russell, 1997). Migrants include a wide spectrum of populations: skilled and unskilled labourers, technical and kindred workers, voluntary or forced migrants moved from their place of origin in response to poverty or lack of employment, for example.

Overseas migration from the poor "South" to the developed "North" has multi-dimensional effects on both the sending and receiving communities (Hadi and Kamal, 1997; Shah and Arnold, 1985). Most studies conducted on this issue have concentrated on the demographic and economic aspects, ignoring the complex social and cultural consequences of international migration (Shah and Arnold, 1985). The social and cultural aspects of overseas migration on the countries of origin have recently been receiving most of the attention, but many studies have methodological problems, particularly in estimating the net effects of international migration on the socio-cultural spheres (Shah and Arnold, 1985). Although a considerable number of studies on the economic impact of South-to-North migration on the sending communities have been conducted (Simmons and others, 1977; Goldstein and Goldstein, 1981), the findings remain inconclusive. For example, Simmons (1984) found migration to be an integral part of socio-economic development and concluded that the effects of migration depend on the context within which migration takes place. On the other hand, migration has been found in several studies to have a very weak and sometimes negative influence on socio-economic development (Durand and others, 1996; Simmons and others, 1977; Dasgupta, 1981).

The key to assessing the impact of migration on economic development is generally considered to be the contribution of remittances sent by the migrants to their families in the source countries. Socio-cultural changes that take place as a result of international migration are considered to operate through the diffusion of secular values along with remittances. The role of remittances in economic development is fairly well known, but their non-economic impact as well as the process through which the remittances and diffusion of values operates in order to change the society and culture remain unknown. Overseas migrants interact with their families and other kin left behind in many ways in terms of the influence they have on them to modify their traditional behaviours and values. In this article, we focus on two forms of influence on those left behind: (a) raising economic conditions through the injection of remittances; and (b) modifying social behaviours through the diffusion of secular ideas in the traditional cultures of the sending communities. The objective of this article is to examine the 
role of the economic and social aspects of overseas migration in raising the well-being of the household members left behind in rural communities of Bangladesh.

\section{Conceptualizing the migration-well-being linkage}

Well-being is a process rather than a static condition, or the status of a situation; there is no universally accepted definition of "well-being". In this study, an attempt has been made to conceptualize well-being ${ }^{l}$ at the household level and focus on the economic and social dimensions only. A number of indicators are used to measure various aspects of socio-economic well-being. As the study conceptualizes the link between overseas migration and various dimensions of well-being of the communities left behind, we seek to examine a number of basic assumptions of the role of international migration on the presumed economic and social well-being of those left belind. These assumptions are based on available empirical evidence that reveals a strong influence of the behavioural aspects of international migration on improvements in the social, economic and health status of those left behind. One set of studies has assumed that the remittances sent by the migrants have little or no economic impact on the sending communities (Durand and others, 1996; Simmons, 1984; Dasgupta, 1981), whereas other studies have found considerable economic development as well as standard of living improvements (Abbasi and Irfan, 1983; Islam and others, 1987; Madhavan, 1985; Russell, 1997).

In examining the effects of overseas migration on well-being, we have looked at three aspects ${ }^{2}$ of migration, namely duration of exposure, intensity of effect and the nature of exposure. Firstly, we assumed that both the amount of remittances and diffusion of secular values greatly increase with the duration of stay of the migrants in overseas areas; thus, the duration of the period abroad is considered to be an important predictor of well-being. Secondly, it is expected that the amount of remittances sent to, and the frequency of contact of the migrants with, those left behind increase with the number of migrants per household; thus, the number of migrants per household is considered to be a predictor of the intensity of impact in both economic and social terms. Thirdly, the behavioural aspects of change among migrants depend largely on the context in which the migrants live and interact. It is assumed that the social and cultural environment is very different in more developed countries such as those in Europe and North America, and Japan in Asia, than in less highly developed conservative countries such as those in the Middle East, and India and Malaysia in Asia. Thus, it is hypothesized that migrants living in developed countries are more 
likely to accept, adopt and promote secular behaviours than migrants not living in such countries.

The possible ways in which overseas migration may influence the different dimensions of human well-being are not clearly known. We focus on two aspects, namely inflow of remittances and diffusion of secular ideas ${ }^{3}$, as vehicles of change in the socio-economic spheres of the households left behind. Remittances are expected to increase household income and the opportunity to save money, and enhance the households' standard of living and income security by providing greater access to and control over resources. Greater availability of remittances may contribute to better housing conditions and increase access to and use of modern health services because the financial resources are sufficient to obtain health care and adequate food.

Reduction of morbidity and decreased mortality are important indicators of human well-being in the conceptual framework of the study. Mortality is indirectly influenced by the economic and behavioural aspects of remittances through improvements in food habits, nutritional status and health-seeking behaviour. As a result of exposure to multi-faceted cultures, the migrant families would have more knowledge about modern health facilities than others. They would be able to obtain necessary health care services and have greater confidence and ability to interact with health care providers. It is hypothesized that the diffusion-effect of overseas migration can modify the health care behaviour of those left behind.

Intense exposure to different cultures may modify traditional patriarchal attitudes towards gender roles and women's status. Also, greater participation in household decision-making occurs when women assume control over the resources of the households as a result of the long-term departure of adult men from the households. The change in women's position, with a greater understanding of the social and cultural factors affecting them, may result in greater mobility, reduce dependence on traditional patrons and increase self-confidence (Hugo, 1997). The presumed relationships depend on a complex set of confounding factors, some of which may have significantly altered or modified the direction of associations between migration and well-being variables. For example, in our study village households of modest means had access to credit facilities to finance, without collateral, family-based micro-enterprises such as farming, poultryand cattle-raising, and vegetable gardening; this facility is not available to relatively better off households. In such a context, the tendency to migrate to acquire capital quickly may be more attractive among the members of the relatively-better off than poorer households. Therefore, overseas migration 
may be a strategy, not only to escape unemployment and poverty (Massey and others, 1993; Russell, 1997), but also to earn money primarily to finance household consumption and secondarily to finance new productive activities. A number of individual and household characteristics, such as educational level, occupation, amount of land owned and religion of the household, influence the effects of overseas migration in terms of the change in well-being of those left behind. Also, the consequences may differ according to the duration, intensity and nature of exposure of migration. We assume and recognize, therefore, that the effects of overseas migration are multi-dimensional, complex and change in context and over time.

\section{Data and methods}

Although official emigration from Bangladesh began in the late nineteenth century (Islain and others, 1987; Hadi and Kainal, 1997), the national migration data from government departments are either incomplete or inaccurate. The data for this study were collected from a demographic surveillance system covering 70 villages located in 10 regions of rural Bangladesh. A complete enumeration of the study villages in 1996 revealed that migrant households were concentrated in a few pockets. Migrant households are defined as households where at least one member either had been living, or returned home, after having lived in a foreign land for at least six months. In total, 530 migrant households were identified; of these, 515 provided information. A comparable number of non-migrant households were randomly selected from the same villages to yield a total of 1,030 sample households for the study. All sample households were interviewed that had provided information on economic conditions, amount of remittances ${ }^{4}$, women's position, educational aspirations and the health status of the study households. The respondents were adult female members of the households.

Because the study focuses on the socio-economic well-being of the members of the households left behind, the unit of analysis of this research is the "household". The sample households are categorized from three migration perspectives: (a) duration of exposure to migration: either non-migrant (migrant for less than 5 years) or migrant (a migrant for 5 years or more), (b) intensity of migration: (i) non-migrant, (ii) only one migrant and (iii) two or more migrants in each household and (c) nature of exposure to migration: (i) non-migrant, (ii) migrant living in a less developed conservative country and (iii) migrant living in a more developed western country. 
The study assumes that overseas migration from villages significantly improves the socio-economic well-being of those left behind in the migrants' households. As there is no universally accepted indicator of well-being, we have considered several proxy measures to understand it. Two dimensions of socio-economic well-being are conceptualized in this research: (a) economic well-being, which is considered to be a process of becoming capable of fulfiling the basic needs of all members of the household; its dimensions are increased by six indicators: ability to save money, raising living conditions, buying land, investing in a house, access to electrical facilities and repaying debt, and (b) social well-being, which refers, to changes in the behavioural aspects of a household's ability to satisfy other needs. Health-seeking behaviour, incidence of death, morbidity, education of children, women's position and practice of giving a dowry are used as indicators of social well-being. In this article, a description is provided of the demographic and socio-economic variables of the study households by duration of exposure of migration. The well-being indicators are differentiated by the duration of exposure. The article also examines the net impact of various dimensions of overseas migration on the well-being variables. Findings based on cross-sectional data may generate biased estimates of the impact of overseas migration on socio-economic well-being because households that are relatively better off may be more likely than others to send their members overseas. To minimize the possibility of selection bias, multivariate analyses have been used to control the effects of confounding factors. Despite these steps, the estimated effects of overseas migration on various dimensions of well-being may tend to distort the findings and the conclusions drawn from them.

\section{Findings}

\section{Profile of the study households}

Information about the samples is summarized in table 1 where the study variables are differentiated by the duration of exposure to overseas migration. Mean household size is significantly higher among migrant than non-migrant households, indicating that the members left behind live in extended rather than nuclear households. When mean age of the members left behind of the non-migrant and migrant households are compared, no significant difference is observed. The differences in the proportion of males in the households indicate that migrants tend to be men. Mean schooling is much higher among the migrant than non-migrant household members, and the percentage of the population with at least a secondary level of education is also significantly higher among the migrant households. Recent migrants are relatively less educated than earlier migrants. 
Table 1. Percentages and means of study variables, by duration of exposure to overseas migration, Bangladesh

\begin{tabular}{lccc}
\hline Study variables & \multicolumn{3}{c}{ Duration of exposure } \\
\cline { 2 - 4 } & None & $<5$ years & 2 5 years \\
\hline Mean household sizes & 5.68 & 6.04 & 6.59 \\
Mean agee & 24.20 & 24.90 & 24.60 \\
Percentage malea & 49.50 & 45.60 & 43.60 \\
Mean schooling (years)b & $1.73(3.1)$ & $2.50(3.7)$ & $3.15(5.5)$ \\
Percentage with grade 10 or higher educationb & 3.70 & 6.20 & 8.80 \\
Mean land owned (acres)c & $0.62(1.49)$ & $2.09(2.57)$ & 3.77 (8.67) \\
Percentage owning land of $\geq 2$ acres c & 23.00 & 36.20 & 44.40 \\
Percentage selling labourc & 42.20 & 4.50 & 3.90 \\
Percentage with access to credit facilities c & 40.90 & 19.40 & 13.10 \\
Percentage Muslimc & 72.40 & 91.00 & 82.40 \\
N & 515 & 362 & 153
\end{tabular}

Note: Standard deviations are shown within parentheses; 1 hectare $=2.5$ acres.

a Calculated by taking into consideration all members of the household.

b All members aged 6 years or older are considered.

c Estimated as household level variable.

At the household level, there appears to be a positive association between the amount of land owned and the duration of exposure to overseas migration, whereas non-migrant households have the least amount of land. It is not known, however, whether the remittances sent to the migrant households have played a role in this regard. The main source of earnings, i.e. the sale of manual labour ${ }^{7}$, is about 42 per cent among the non-migrant households compared with less than 5 per cent in the migrant households. NGO-led credit facilities are generally available to the bottom 50 per cent economically of the households in the study villages. The distribution of access to credit facilities indicates that migrant households are generally less poor and have limited access to the local credit market. Overseas migration was found to be higher among Muslims than other religious groups in Bangladesh.

\section{Migration and economic well-being}

Regarding the impact of overseas migration and duration of exposure on the economic indicators of well-being, it is clear that the remittances sent by the migrants can contribute towards the ability of the household members left behind to save money and improve their standard of living (table 2). The capacity to buy land, invest in building or repairing a house, and repay debt is also positively associated with the length of staying abroad. 
Table 2. Indicators of economic well-being, by duration of exposure to overseas migration, Bangladesh

\begin{tabular}{lccc}
\hline Economic indicator & \multicolumn{3}{c}{ Duration of exposure } \\
\cline { 2 - 4 } & None & $<$ 5years & $\geq \mathbf{5}$ years \\
\hline Ability to save money & 12.1 & 24.2 & 29.6 \\
Raising living conditions & 32.4 & 49.4 & 51.0 \\
Buying land & 8.6 & 23.9 & 30.7 \\
Investing in a house & 39.0 & 39.3 & 40.5 \\
Access to electrical facility & 15.5 & 40.6 & 62.1 \\
Repaying debt & 25.1 & 47.5 & 35.3 \\
\hline
\end{tabular}

The net effects of the duration, intensity and nature of exposure to overseas migration on six dimensions of economic well-being are summarized in table 3. The regression equations are controlled for educational level, occupation, amount of land owned, amount of remittances, religion and access to credit facilities of the household head. Because the explanation of the effects of control variables on well-being indicators is relevant but not very important in our analysis, their estimates are not shown in the table. Data show that the duration of exposure is statistically significant for four of six indicators of economic well-being: raising living standards, buying land, access to electricity and repaying debt. When the duration becomes five years or more, the odds ratios of most indicators tend to increase or stabilize, except for living conditions and repayment of debt. These findings demonstrate that the longer a migrant is exposed to life in an overseas country, the greater is the likelihood that the household members of that migrant who are left behind will have a better living standard.

The assumption that the intensity of exposure to overseas migration, measured by the number of migrants in each household, will have a significant positive effect on the economic well-being is found to be valid for each of the indicators. The intensity of impact is found to be particularly important in raising living conditions, buying land and repayment of debt. It is very difficult to explain why the economic well-being indicators, such as living conditions, purchasing land or access to electrical facilities, would be better in households having migrants in western countries than in those having them in conservative countries even when the amount of remittances is controlled. Because the amount of remittances sent to the households is the key determinant of their economic well-being, it is quite possible that the chance to earn more money is higher in the more developed western countries than in conservative developing countries, even when the experience and skills of migrants working in the two types of countries are similar. 
Table 3. Odds ratios for selected economic indicators of well-being, controlling for education level, occupation, amount of land owned, amount of remittances, religion and access to credit facilities of the household head, Bangladesh

\begin{tabular}{|c|c|c|c|c|c|c|}
\hline \multirow{2}{*}{$\overline{\text { Migration type }}$} & \multicolumn{5}{|c|}{ Economic well-being } & \multirow[b]{2}{*}{$\begin{array}{c}\text { Repaying } \\
\text { debt }\end{array}$} \\
\hline & $\begin{array}{l}\text { Ability to } \\
\text { save money }\end{array}$ & $\begin{array}{c}\text { Lving } \\
\text { conditions }\end{array}$ & $\begin{array}{l}\text { Buying } \\
\text { land }\end{array}$ & $\begin{array}{l}\text { Investing } \\
\text { in house }\end{array}$ & $\begin{array}{l}\text { Access to } \\
\text { electricity }\end{array}$ & \\
\hline \multicolumn{7}{|c|}{$\begin{array}{l}\text { Duration of exposure } \\
\end{array}$} \\
\hline None & 1.00 & 1.00 & 1.00 & 1.00 & 1.00 & 1.00 \\
\hline$<5$ years & 1.12 & $1.52^{b}$ & $1.68 \mathrm{~b}$ & 1.07 & $1.73 \mathrm{c}$ & $4.80 c$ \\
\hline$\geq 5$ years & 1.17 & 1.42 & $1.99 b$ & 1.08 & $3.67 \mathrm{c}$ & $3.11^{\mathrm{c}}$ \\
\hline \multicolumn{7}{|c|}{ Number of migrants } \\
\hline None & 1.00 & 1.00 & 1.00 & 1.00 & 1.00 & 1.00 \\
\hline One & 1.06 & $1.41^{\mathrm{b}}$ & $1.73 \mathrm{~b}$ & 1.06 & $2.01 \mathrm{c}$ & $4.18 \mathrm{c}$ \\
\hline Two or more & 1.58 & $2.06 \mathrm{c}$ & $2.02^{b}$ & 1.15 & $3.32 \mathrm{c}$ & $5.05 \mathrm{c}$ \\
\hline \multicolumn{7}{|c|}{ Type of country where migrant lives } \\
\hline None & 1.00 & 1.00 & 1.00 & 1.00 & 1.00 & 1.00 \\
\hline Conservative & 1.09 & $1.46^{\mathrm{b}}$ & $1.76^{\mathrm{b}}$ & 1.08 & $2.10^{c}$ & $4.42 \mathrm{c}$ \\
\hline Western & 1.90 & $2.25 \mathrm{~b}$ & $1.96 \mathrm{a}$ & 1.16 & $3.70 \mathrm{c}$ & d \\
\hline
\end{tabular}

$a=p<0.10 ; b=p<0.05 ; c=p<0.01 ; d=$ Sample size is too small to estimate.

\section{Migration and social well-being}

Indicators of social well-being also increase with the duration of exposure to migration (table 4). For example, seeking health care from a qualified physician is significantly higher among migrant than non-migrant households and this behaviour increases in line with the duration of exposure. Similarly, the incidence of both mortality and morbidity is lower among migrant than non-migrant households. Also, the value of education is better understood by the members of the migrant households than their non-migrant counterparts. The women in the migrant households enjoy a better position than those in non-migrant households. Certain types of nuptial behaviour, such as the practice of giving dowry in marriage, is significantly less among the migrant than non-migrant households.

The effects of duration of exposure are estimated in table 5, from which it is clear that overseas migration has some positive effects $(p<0.05)$ on migrant households with regard to their seeking modern health care in the event of illness. This is probably because migrant households are financially better off and can better afford to visit a qualified practitioner than can members of a non-migrant household (Hadi and Kamal, 1997). Also, the diffusion effect of secular ideas may have played a role in 
Table 4. Indicators of social well-being, by duration of erposure to overseas migration, Bangladesh

\begin{tabular}{lccc}
\hline Social indicator & \multicolumn{3}{c}{ Duration of exposure } \\
\cline { 2 - 4 } & None & $<5$ years & $\geq \mathbf{5}$ years \\
\hline Health-seeking behaviour & 47.0 & 68.0 & 75.2 \\
Incidence of death & 16.5 & 12.6 & 13.7 \\
Morbidity & 45.9 & 41.6 & 43.8 \\
Education of children & 54.4 & 78.0 & 83.1 \\
Women's position & 9.6 & 28.7 & 22.2 \\
Nuptial behaviour & 59.9 & 38.0 & 16.9 \\
\hline
\end{tabular}

modifying the health-seeking behaviour of the migrant households through frequent contacts between the migrants and their household members left behind. Ability to spend money for health care increases with the duration of stay overseas. This trend is quite distinct, which indicates that the intensity of the effect (or the number of migrants per household) not only raises the level of earnings and remittances per household but it also significantly multiplies the diffusion effect on the migrant households. The diffusion of secular values is assumed to play an important role in modifying behaviours, while it is also expected that the diffusion process depends on the social and cultural environment where the migrants live and interact. We assumed that migrants in more developed western countries would have a more secular outlook than migrants living in relatively conservative countries. As expected, the modern health-seeking behaviour is significantly higher in households having migrants living in western countries than in those having migrants living in conservative countries. We found that morbidity is lower among migrant households than other households, as has been found in other studies (Parasuram, 1986), although the difference is not statistically significant. The data also support this notion, that overseas migration has negative effects on morbidity among people left behind when other variables are controlled. As with morbidity, the incidence of mortality appears to have a negative association with the duration, intensity and nature of exposure to migration. We have seen previously that the remittances as well as diffusion of cultural values have significantly modified the health-seeking behaviour of the household members left behind (Brittain, 1990). Better living conditions may also have reduced the incidence of illness which, along with modern health-seeking behaviour, may contribute significantly to reducing the incidence of mortality (Hadi and others, 1997).

Sending children to school in a traditional community is considered an important indicator of social well-being as a significant proportion of 
Table 5. Odds ratios for selected social indicators of well-being, controlling for educational level, occupation, amount of land

owned, amount of remittances, religion and access to credit facilities of the household head, Bangladesh

\begin{tabular}{|c|c|c|c|c|c|c|}
\hline \multirow{2}{*}{ Milgration type } & \multicolumn{5}{|c|}{ Social well-being } & \multirow[b]{2}{*}{$\begin{array}{l}\text { Nuptial } \\
\text { behaviour }\end{array}$} \\
\hline & $\begin{array}{l}\text { Health } \\
\text { behaviour }\end{array}$ & $\begin{array}{l}\text { Incidence } \\
\text { of mortality }\end{array}$ & $\begin{array}{l}\text { Morbidity } \\
\text { rate }\end{array}$ & $\begin{array}{l}\text { Education } \\
\text { of children }\end{array}$ & $\begin{array}{l}\text { Women's } \\
\text { position }\end{array}$ & \\
\hline \multicolumn{7}{|c|}{ Duration of exposure } \\
\hline None & 1.00 & 1.00 & 1.00 & 1.00 & 1.00 & 1.00 \\
\hline$<5$ years & $1.59^{\circ}$ & $0.63^{\mathrm{a}}$ & 0.86 & $2.14^{\mathrm{b}}$ & $2.09^{c}$ & 0.70 \\
\hline$\geq 5$ years & $1.90^{\mathrm{c}}$ & 0.66 & 0.95 & $2.29^{b}$ & $2.09^{b}$ & $0.25^{c}$ \\
\hline \multicolumn{7}{|c|}{ Num ber of migrants } \\
\hline None & 1.00 & 1.00 & 1.00 & 1.00 & 1.00 & 1.00 \\
\hline One & $1.53^{b}$ & $0.60^{c}$ & 0.86 & $1.98^{\mathrm{b}}$ & $2.30^{c}$ & $0.56^{b}$ \\
\hline Two or more & $3.10^{c}$ & 0.82 & 1.05 & $3.53^{\mathrm{b}}$ & 1.14 & $0.50^{b}$ \\
\hline \multicolumn{7}{|c|}{ Type of country where migrant lives } \\
\hline None & 1.00 & 1.00 & 1.00 & 1.00 & 1.00 & 1.00 \\
\hline Conservative & $1.60^{\mathrm{c}}$ & $0.61^{\mathrm{c}}$ & 0.88 & $2.24^{c}$ & $1.96^{\mathrm{c}}$ & $0.56^{b}$ \\
\hline Western & $6.38^{c}$ & d & d & 1.32 & $6.51^{\mathrm{c}}$ & d \\
\hline
\end{tabular}

$a=p<0.10 ; b=p<0.05 ; c=p<0.01 ;^{d}=$ Sample size is too small to estimate.

school-aged children remain out of school. The data show that the role of overseas migration has a significantly positive effect on raising school enrolment. The aspiration for the education of children increases with the length of stay and intensity of exposure to migration (Gilani, 1983), indicating that both the remittances and secular values have played an indirect role in modifying behaviours relevant to the education of children (Roongshivin, 1985).

The practice of giving dowry for marriage, particularly among the poorer strata of society, is widespread in Bangladesh (Amin and Hadi, 1998), even though receiving a dowry is illegal. The dowry system has remained culturally acceptable to the wider community, however, there is a small section of society who consider the practice of dowry to be urong and unjust, arguing that the sanction against it should be enforced. Overseas migration appears to play a negative role with regard to the practice of dowry, even if the amount of remittances sent to the dependent households is controlled (table 5). Our assumption is that the diffusion effect of secular values from other countries through international migration will reduce the practice of giving dowries among migrant households. Although the capacity of migrant households to spend money in the form of providing dowries is higher than their non-migrant counterparts, because the migrant households 
are better able to save more money than non-migrant households (Gulati, 1983), none of the households with migrants living in western countries reported providing dowries, which clearly demonstrates the diffusion effect of secular values on entrenched cultural behaviour.

The process of empowerment in a patriarchal society is considered to be an important dimension of social change. Reductions in gender inequality and improvements in women's position in the household as well as in the community are expected to increase the overall well-being of people. Women's position, measured as the extent to which women can decide or actively participate in the household decision-making processes, is positively and statistically significantly $(p<0.01)$ associated with the duration, intensity and nature of exposure to international migration. In many cases, the households left behind are headed by women because of the prolonged absence of adult men. Thus, women in the migrant households are forced to play additional domestic roles (Hadi and Kamal, 1997). In the absence of men, women are not being dominated by men (Khafagy, 1982; Hadi and Kamal, 1997), a situation that also substantially increases their role in decision-making (Shah and Arnold, 1985; Shaheed, 1981; Gulati, 1983). Women's status increases in line with the duration of adult men's stay overseas. The diffusion effect also plays a significant role in other ways as the women who have family members living in western countries are more likely to enjoy more freedom than others. The absence of men encourages women to play a major role in managing the household (Gulati, 1983); further, it enhances their ability to develop independently and helps them to cultivate new interests and discover hidden potentials (Go and others, 1983).

\section{Conclusions and implications}

Within the framework of the migration of individuals, this research integrates economic, social and behavioural aspects of the households affected by the inflow of remittances and diffusion of secular values from overseas. The findings extend those of previous studies and highlight the importance of South-to-North migration for raising living standards and changing social behaviour in a developing country setting (Islam and others, 1987; Madhavan, 1985; Russell, 1997). Aspects of migration, such as duration of exposure, intensity of effect and the nature of exposure, are shown to be major predictors of influence on those left behind. The predictor variables explaining most of the indicators of well-being are shown to be statistically significant.

Previous studies on the role of remittances in improving the economic and social spheres of those left behind are not conclusive regarding 


\section{Endnotes}

1. Well-being at the family level is the process of improving all spheres of human life. For simplicity, we have narrowed the concept to two dimensions: economic and social. Six indicators are estimated to measure each dimension, recognizing the fact that the indicators have only partially reflected the well-being of the family.

2. Three types of overseas migration are used in this study since the purpose of the research has been to understand all possible kinds of effects of migration on those left behind.

3. By secular ideas we mean modern, progressive and scientific approaches to understanding and explaining any issue, event or change etc.

4. The amount of remittances is used as a control variable along with educational level, occupation, amount of land owned, religion and access to credit facilities. The remittance data for the previous five years were collected retrospectively, i.e. by asking the respondents for details. The actual amount of remittances sent to the households left behind was difficult to measure since remittance-related records are not generally preserved in most households. Thus, the amount of remittances calculated may not be very accurate.

5. Economic well-being is measured by using a set of proxy variables as follows:

(a) Ability to save money. The income and expenditure of the household for the one year preceding the survey were est imated by asking the respondent for details. If the income of the household was higher than the expenditure, the household was considered to be "able to save money".

(b) Raising living conditions was based on self-assessment of the standard of living during the previous five years by the household members. The consumption of food, and expenditures on clothes and other basic necessities were considered in assessing the changes in living conditions.

(c) Buying land: As the rural economy is primarily agricultural, the land in Bangladeshi villages has remained as the major source of income. Buying land during the previous five years was considered as a measure of economic well-being at the household level.

(d) Investing in house: After fulfiling the basic necessities, the tendency among the better-off rural households has been to build or renovate their living quarters. The respondents were asked whether they invested money in building or renovating their house during the previous five years.

(e) Access to electricity was considered as both a status symbol and an indicator of living conditions since most of the households in the study villages had no electrical facilities in their houses.

(f) Repaying debt was measured by asking whether the household was able to pay off debt during the previous year. Ability to repay a loan was considered to be an indicator of economic well-being.

6. Social well-being is understood by the following indicators:

(a) Health-seeking behaviour depends not only on financial capacity but also on the perceptions of the household members about illnesses and their remedies. The respondents were asked to report the measures taken by them at the time of illness of any household member during the previous one-year period. The use of modern health care facilities, such as seeking advice from qualified physicians or certified rural medical practitioners, was considered "modern" and seeking help from spiritual healers, quacks etc., was considered "traditional" health behaviour.

(b) Incidence of mortality: Prevention of premature death was an indicator of well-being. The variable indicates the occurrence of premature death in the household during the previous five years. 
long-term effects. Major concerns are whether South-to-North migration is beneficial or detrimental to development efforts in the long run, whether it reduces or increases inequalities in income distribution, or whether it reduces the pressure of unemployment among educated youths (Fergany, 1982; Madhavan, 1985). Although overseas migration from Bangladesh has been a continuous process for a long time, the rate of international migration has remained relatively very insignificant. Earlier studies have indicated that the demographic consequences of out-migration are negligible at the national level. Our study clearly indicates that there are some positive changes in terms of a better standard of living as a result of the inflow of the remittances. In view of the pressure of unemployment among educated youths and the fact that a large proportion of recent migrants come from poor households, it is unlikely that South-to-North migration would be detrimental to economic development, or would increase economic inequalities in society. With respect to the flow of remittances along with familial exchanges with those left behind, our analysis leads us to conclude that migrants who earn money and stay abroad longer are more likely to be able to save money and invest the remittances in less productive sectors than non-migrants. The economic well-being of those left behind depends on the intensity and duration of exposure as well as the possibility of earning and sending more money to their dependants at home. Although most of the remittances sent to family members usually goes towards consumption, the remittances along with the diffusion of knowledge have the potential to modify the socio-cultural behaviour of those left behind. The intensity and direction of the change in behaviour depend on the context. The possibility of a behavioural change is very low if the migrants live in a relatively less developed closed society compared with living in an advanced and open culture.

The assumptions of the contribution of overseas migration to those left behind, developed and tested in this study, suggest that the flow of remittances along with the diffusion of secular values from the North to the South are key processes through which various forms of migration operate to improve the socio-economic well-being of those left behind in the sending communities. This approach helps to explain earlier misconceptions about why international migration has produced differential or undesirable outputs in developing-country settings. With increasing globalization of economies, the magnitude of South-to-North migration is likely to grow in coming decades (Skeldon, 1998). Governments as well as private foundations should play a facilitating role by providing appropriate structures for the spending of remittances and modify the livelihood as well as the behaviour of the migrant communities. 
(c) Morbidity. Illness of any household member destabilizes the well-being of the household. Morbidity was measured by asking whether any member of the household was ill during the previous three months.

(d) Education of children: Access to school for all eligible children (aged 6-15 years) was considered an indicator of social well-being. Education of children was measured by asking whether all eligible children in the household were enrolled in school during the time of the survey.

(e) Women's position was measured by asking whether a woman could make her own decisions or could actively participate in the decision-making processes within the household. Decision-related issues include: education for children, type of treatment to be given for herself or her children, whether or when to visit birthplace or other places, amount of money to be spent on behalf of family members during festivals, and whether or how much money should be lent to or borrowed from others.

(f) Nuptial behaviour. Dowry practices are widespread in rural Bangladesh, although a smaller section of the community considers it improper. Nuptial behaviour was measured by asking whether any member of the household received or provided dowry in marriages during the previous five years.

7. The concept of "sale of labour" of a household is extensivelyused by NGOs in identifying the poorer sections of a community. A household was considered poor if any aduit member of that household sold his or her manual labour services for at least 100 days a year and owned cultivable land of 50 decimals ( 1 decimal = one-hundredth of an acre) or less.

\section{References}

Abbasi, N. and M. Irfan (1983). "Socioeconomic effects of international migration on the families left behind". Paper presented at the Conference on Asian Labor Migration to the Middle-East, East-West Population Institute, Honolulu, 19-23 September.

Amin, F.D. and A. Hadi (1998). "Micro-credit programs, women's empowerment and change in nuptiality in Bangladesh villages". Paper presented at the 1988 Annual Meeting of the Population Association of America (PAA), Chicago, 2-4 April.

Brittain, A.W. (1990). "Migration and the demographic transition: a West Indian example" Social and Economic Studies 39(3):39-64.

Dasgupta, B. (1981). "Rural-urban migration and rural-urban development", in: J. Balan (ed.) Why People Move? (Paris, UNESCO Press).

Durand, J., W. Kandel, E.A. Parrado and D.S. Massey (1996). "International migration and development in Mexican communities" Demography 33(2):249-264.

Fergany, N. (1982). "The impact of immigration on national development in the Arab region: the case of Yemen Arab Republic" Intemational Migration Review 16(4):757.780.

Gilani, I. (1983). "Overview of stocks and flows of migrants and the social and familial impacts on communities and households in districts of high labor migration". Paper presented at the Conference on Asian Labor Migration to the Middle East, East-West Population Institute, Honolulu, 19-23 September.

Go, S.P., L.T. Postrado and P.R. Jimerez (1983). The Effects of Intemational Contract Labor (Philippines), Vol. 1 (Manila: Integrated Research Center, De La Salle University).

Goldstein, S. and A. Goldstein (1981). Surveys of Migration in Developing Countries: $A$ Methodological Review (Honolulu: East-West Population Institute). 
Gulati, L. (1983). "Impacts of male migration to the Middle East on the household: some evidence from Kerala, India". Paper presented at the Conference on Asian Labor Migration to the Middle East, East-West Population Institute, Honolulu, 19-23 September.

Hadi, A., S.R. Nath and A.M.R. Chowdhury (1997). "Improving living condition of the poor: role of poverty-focused development programs". Unpublished manuscript (Dhaka: Research and Evaluation Division, BRAC).

Hadi, A. and F. M. Kamal (1997). "Demographic and socio-cultural consequences of international migration in rural Bangladesh". Paper presented at the International Population Conference, IUSSP, Beijing, 11-17 October.

Hugo, G. (1997). "Migration and female empowerment". Paper presented at the Seminar on Female Empowerment and Demographic Processes: Moving Beyond Cairo, IUSSP, Lund, Sweden, 21-24 April.

Islam, M., H. Chowdhury, M. Salehuddin, J.P. Dutta, M. Ali and A.K. Hoque (1987). Overseas Migration from Rural Bangladesh: A Micro Study (Chittagong: University of Chittagong).

Khafagy, F.A. (1982). "Socio-economic impact of emigration from El-Quebabat village" Population Studies (61):39-45.

Madhavan, M.C. (1985). "Indian emigrants: numbers, characteristics, and economic impact" Population and Development Review 11(3):457-481.

Massey, D., J. Arango, G. Hugo, A. Kouaouci, A. Pellegrino and J.E. Taylor (1993). "An evaluation of international migration theory: the North American case" Population and Development Review 20(4):699-751, 921, 923.

Parasuram, S. (1986). "Migration and its effect on family" Indian Joumal of Social Work $47(1): 1-14$.

Roongshivin, P. (1985). "Some socio-economic consequences of Thailand's labor migration to the Middle East", in: International Migration in the Pacific, Sri Lanka and Thailand (New York: United Nations ESCAP).

Russell, S.S. (1997). "International migration: implications for the World Bank", in: Working Paper, Human Capital Development and Operations Policy (Washington, D.C.: World Bank).

Shah, N.M. and F. Arnold (1985). "The non-economic consequences of Asian labour migration to the Middle East" Intemational Population Conference, Vol. 3, IUSSP.

Shaheed, F. (1981). "Migration and its effects on women in the village of Provenance". Paper presented at the Tripartite Asian Regional Seminar, Rural Development and Women, Mahabaleshwar, India, 6-11 April.

Simmons, A.B., S. Diaz-Briquets and A.A. Laquian (1977). Social Change and Intemal Migration: $A$ Review of Research Findings from Africa, A sia and L atin America (Ottawa: International Development Research Centre).

Simmons, A.B. (1984). "Migration and rural development: conceptual approaches, research findings and policy issues", in: Population Distribution, Migration and Development. Proceedings of the Expert Group on Population Distribution, Migration and Development (New York: United Nations).

Skeldon, R. (1998). "Urbanization and migration in the ESCAP Region" Asia-Pacific Population Joumal 13(1):3-24. 